\title{
Experiment designing in operating investigations of subassembly of the marine energy systems
}

\author{
Jan Monieta ${ }^{1, *}$ \\ ${ }^{1}$ Maritime University of Szczecin, Wały Chrobrego 1-2, 70-500 Szczecin, Poland
}

\begin{abstract}
To choose the receive locations of diagnostic signals, reliability and preliminary investigations were applied. The functional systems and the most unreliable subassemblies were determined. The studies were conducted for the auxiliary marine engines with the same rated speed and fueled with same distillation and residual fuels. In the article a choice of the ship's object, which has a significant impact on reliability, operating costs and the functions performed, is presented. Reliability, economic and risk of exploitation investigations were carried out, which allowed selecting the facility with the highest failure, costs of adverse events and threat to the natural environment. The research covered the objects of a ship owner operating mainly bulk cargo vessels for mass transport and their essential assemblies - combustion engines.In order to obtain a reasonable amount of information on the state of the examined combustion engine, the following experimental planning methods were used: experiment type, essential elements, location of measurement sensors, measured quantities, test conditions, measurement frequencies, measurement data analysis and inference methods, etc.The reliability indicators and preliminary diagnostic tests were used to select the diagnostic signal reception points. Functional systems and the most unreliable subassemblies were defined in this way. The tests were carried out for auxiliary marine engines with the same rotational speed and fueled by distillation and residual fuels. The tests were conducted for several types of combustion engines.
\end{abstract}

\section{Introduction}

Floating objects are required to minimize threats to people and the environment, the highest efficiency, quality, minimum operating costs, safety, high reliability, etc. [1, 10]. As a result, the complexity of these objects, the power of the propulsion systems, while striving to reduce the size, increases. Therefore, the demands for people involved in the design, manufacture and operation of ship machinery and processes performed by them are increasing. Thus, the works are carried out to improve reliability, efficiency and reduce harmful pollution, vibrations and noise of floating objects [12].

\footnotetext{
* Corresponding author: j.monieta@am.szczecin.pl
} 
Designing of diagnostic experiments in relation to marine combustion engines was carried, among others, by the authors of the works [3, 9, 10, 12, 14]. Used diagnostic procedures for planning experiments included selection: research facilities, the technical characteristics of the object, of the diagnostic parameters and locations of observation and diagnostic symptoms. To include the reasonable amount of information on the state of the internal combustion engine test, use the methods of experiment planning to make the choice: the type of experiment, the sensors locations, measured values, test conditions, frequency of measurements and methods of reasoning.

\section{Planning of diagnostic experiments}

A properly planned and carried out experiment is the starting point for further organized activities, the result of which should be a diagnosis of the object's condition. The basic element of the experiment is measurement, which is the process of receiving and processing information about the value in order to obtain a quantitative result for transmission in space and time through registrations, mathematical development or application to control [15]. One of the measures of informativeness is the quotient of a number of measurements necessary to implement a given program to the number of measurements of the complete program. The development of the theory of experiment was determined by the following facts [15]:

- the combinations number of values exceeds the possibility of conducting tests,

- not all factors cannot be tested separately,

- $\quad$ are factors whose values cannot determined or are unmeasurable and unknown.

The experiment theory is aimed at improving the efficiency of scientific research, as a quotient of the quantity and quality of information to the costs and time research incurred [15]. For complex objects, it is required to include $n$ factors and measurements:

$$
m=m_{1} m_{2} \ldots m_{i} \ldots m_{n}
$$

where:

$m \quad-\quad$ number of measurements,

$m_{i} \quad-\quad$ i-th factor,

$n \quad-\quad$ n-th factor.

A need to determine the functions of many variables in the form of:

$$
Y=F\left(x_{1}, x_{2}, \ldots, x_{i}\right)
$$

where:

$m \quad-\quad$ vector output quantitiess,

$F \quad-\quad$ function,

$x_{i} \quad-\quad$ input quantity.

A feature of some classical methods is factor analysis, as estimation of the frequency of events subjected to testing, randomization, sequential inference, selection of information from studies, statistical analysis, etc. $[7,8,15]$. The possibilities of isolating dominant factors were also addressed in order to avoid overly complex models.

\section{State of knowledge}

The authors of the works, among others, designed diagnostic experiments in relation to internal combustion engines $[2,9,12,14,15]$. The applied procedures of planning diagnostic experiments included the selection of: research objects, features of the technical state of the object, diagnostic parameters and observation sites as well as diagnostic symptoms. In order 
to take into account a reasonable amount of information on the condition of the combustion engine under test, the following experimental planning methods shall be selected: type of experiment, location of measurement sensors, measured quantities, test conditions, measurement frequency and inference methods. Diagnostic actions result in a large set of diagnostic parameters, so there is a need to select relative attributes.

Selection of engine's parameters and conditions of taking measurements or registering vibration signal are usually based on references, researcher's experience or intuition. The article presents exemplary vibroacoustic diagnostics of combustion engine [13]. Selection of test points of vibration on the basis of impact tests' results was suggested.

For a more efficient and environmentally friendly ship operation, a number of measures have been proposed [5]: the introduction of the electronically controlled versions of marine engines, in which the fuel injection and outlet valve opening/closing timings can be controlled and the engine can operate in various modes with high efficiency and low emission, the application of the outlet gas bypass, the usage of turbochargers with variable geometry turbines and the installation of waste heat.

In cases where a set of parameters is numerous and the values of these parameters are similar, there the authors proposed a methodology for classification of acquired diagnostic parameters. This method can be used to build a diagnostic parameter ranking that divides the set of diagnostic variables into stimulators, dissimulators and nominators. Input quantities limited to three elements, i.e. engine shaft speed, engine torque and fuel injection advance angle, were taken into account. Range of output values: carbon dioxide condensation in the outlet manifold, hydrocarbon condensation in the outlet manifold, nitrogen oxide condensation in the outlet manifold, outlet gas temperature and excess air ratio.

\section{Results and analysis}

A motor vessel is a complex system, which is why it is important to choose an object for diagnostic tests. The system is the set of elements called objects, related to each other and the relationships between elements $R$ :

$$
O=\left\{O_{1}, O_{2}, \ldots, O_{n}, R_{1}, R_{2}, \ldots, R_{m}\right\}
$$

where :

$O_{1} \quad-\quad$ Element of the system ) $\mathrm{O}, \mathrm{i}=1,2, \ldots, \mathrm{n}$,

$R_{j} \quad-\quad$ relationships between elements of the system, $\mathrm{j}=1,2, \ldots, \mathrm{m}$.

The significance of the subsystem can be determined by the set of criteria and is the function of the degree of fulfillment of the conditions set by $C_{r i}$ criteria:

$$
I=f\left(C_{r 1}, C_{r 2}, \ldots, C_{r i}, \ldots, C_{r n}\right)
$$

where :

$C_{r i} \quad-\quad$ criteria $1,2, \ldots, \mathrm{n}$.

In the bulk carrier you can also selected the important elements, among others, on the basis of the frequency and costs of adverse events $[4,10]$. For the selected populations of ships the measure of those losses $L$ for a period $(\tau, \tau+\Delta \tau)$ can be described by the relationship [10]:

$$
L(\tau, \tau+\Delta \tau)=\sum_{i=1}^{n(\tau, \tau+\Delta \tau)} L_{i}
$$

where :

$L_{i} \quad-\quad$ collective loss of the $\mathrm{i}$-th of the event in the period $(\tau, \tau+\Delta \tau)$

$n \quad-\quad 1,2, \ldots, \infty$ is the number of adverse events in this period. 
Collective losses can be presented in relative formulate $L_{c i}$ and expressed as a percentage:

$$
L_{c i}=\frac{L_{i}}{L(\tau, \tau+\Delta \tau)} 100 \%
$$

The measure used to assess the safety is the risk of losses of the object. For to the risk assessment was adopted the qualitative and quantitative safety criteria [11]:

$$
R=f \cdot E
$$

where :

$R \quad-$ risk,

$f \quad-\quad$ frequency of occurrence of an accident sea,

$E \quad$ severity of the effect of case.

The risk of the accident is defined as the product of the probability of the risks and consequences of the accident:

$$
R_{a}=P_{i} \cdot C_{i}
$$

where :

$R_{a} \quad-\quad$ Risk of an accident,

$P_{i} \quad-\quad$ Probality of the risks,

$C_{i} \quad$ consequences of the accident.

The greatest losses were caused by fires in marine propulsion units, which described adverse events with significant losses affecting the safety of the crew and the environment. The evaluations show that neither the quantitative nor the economic analyses are satisfactory, but the risk analysis.

The research covered a period of 12 years in which 1040 adverse events were analyzed. This is a sufficient sample to conclude on the state of the population. Maritime ship to transport of bulk cargo was divided into a deck and machinery equipment, and functional systems. It was decided to decomposition the ships taking into account the literature and book of Safety Management Systems of the company. Separated systems have been allocated to deck and engine room crew [10].

The unreliability function, i.e. the probability of damage to the functional system (element) for a fixed instant is [9]:

$$
P^{*}(\tau)=\frac{m(\tau)}{n}
$$

where :

$m(\tau) \quad-\quad$ number of objects damaged in the time interval $\langle 0, \tau\rangle$,

$n-$ number of examined objects.

Fig. 1 the results of reliability tests for 3 tested engines of the same type and fueled with residual fuels are presented. The results also depend on the assumed of engine damage and the boundary in the serving systems. For tests carried out for internal combustion engines driving generators fueled distillation fuels, the most unreliable system was the feed system [9], and for the same type of engine, but adapted to residual fuel combustion, the lubrication system turned out to be the most unreliable. Frequent works on oil are replacement from contamination with combustion products. Feed and lubrication systems also the most unreliable components of the injector and oil filter have the significant impact on energy effects and the environment.

The usefulness of various signals and measures is presented in various works [11]. This work presents the design of an experiment for vibration acceleration and fuel pressure signals in injection subsystem. Because the feed system turned out to be the most frequently failing 
engine system, the influence of the signal reception site on the level of measures in various domains was studied.

Fig. 2 presents the impact of the place of mounting the vibration acceleration sensor on the signal courses. The signals from various measuring points are synchronized.

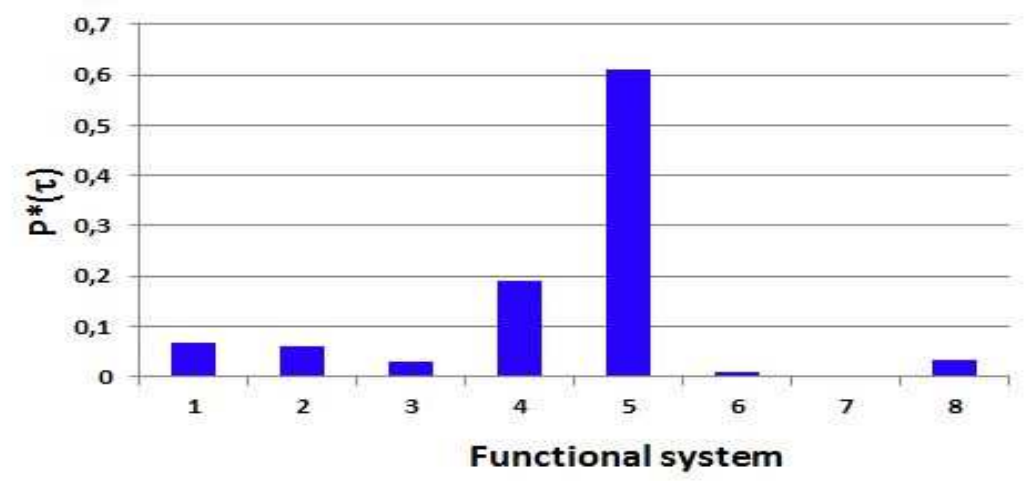

Fig. 1. Diagram of the probability of the unserviceableness state of functional systems of marine engines fuelled by residual fuels: 1 - block, 2 - piston-crank, 3 - exchange, 4 - starting air, 5 - feed, 6 - lubricating, 7 - cooling, 8 - control

Fig. 3 presents the results of research on the influence of the vibration acceleration signal direction on the values of amplitude estimates and kurtosis for 4 tested cylinders of combustion engine, at the same engine load. The highest values of the amplitude estimate were obtained for the sensor with signals received along the injection pipe.

The engine operating conditions are determined by: the ambient conditions, the control of the engine by the operator and the moment of resistance depending on the character of work performed by the engine. The engine work is characterized by set $\boldsymbol{Z}$ that is a sum of the sets of the engine conditions and engine operating states [2]:

$$
Z=W \cup T_{s}=\left\{Z_{1}, Z_{2}, \ldots, Z_{\text {in }}\right\}
$$

where :

$Z \quad-$ set,

$W \quad-\quad$ engine conditions,

$T_{s} \quad-\quad$ engine operating states.

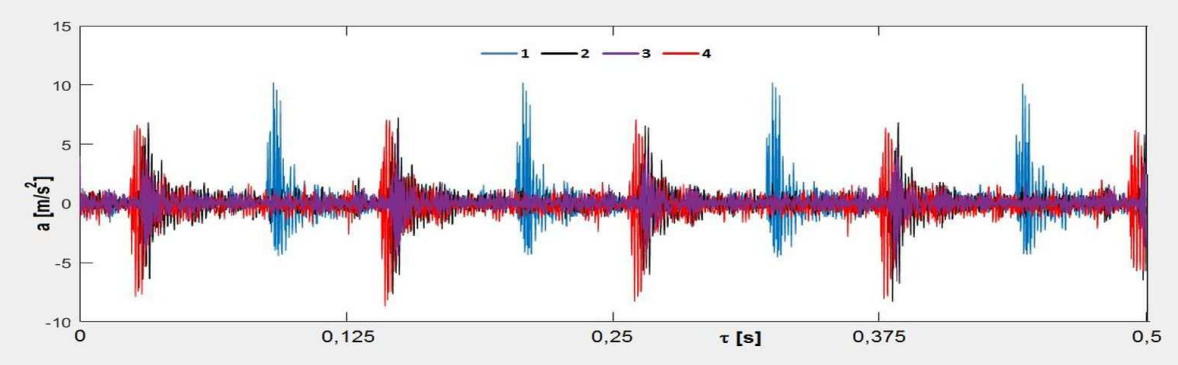

Fig. 2. Impact of the location of the vibration acceleration sensor on the course of the vibration acceleration signal: $1 \div 4$ - sensor attachment points 


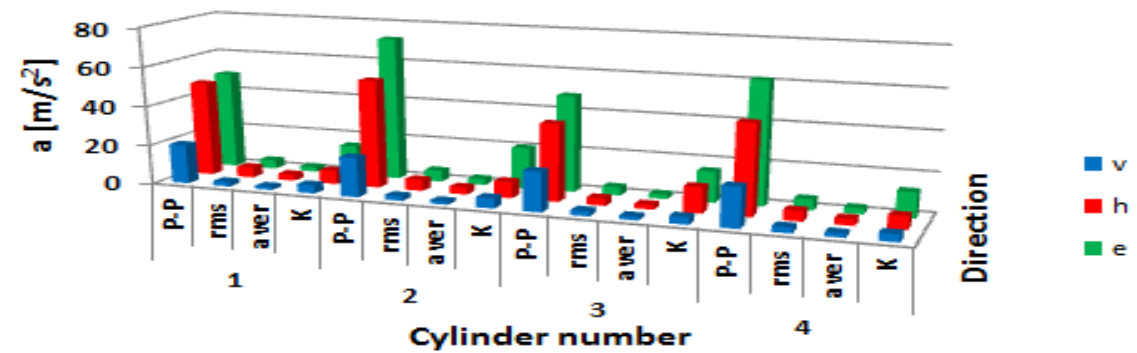

Fig. 3. The influence of the vibration acceleration signal reception direction on the values of amplitude estimates and kurtosis for 4 tested cylinders of one engine: P-P - peak to peak, rms - root-mean-square value, aver - average value, $\mathrm{K}$ - kurtosis, $\mathrm{v}$ - vertically, $\mathrm{h}$ - horizontally, e - along

\section{Selection of signals and diagnostic parameters}

The reduction of the signal vector was done in preliminary tests, from which the useful one was selected. The basis for the selection was the correlation matrix for the selection of parameters independent of each other, and at the same time having very close links to the independent variable. It consists in determining the correlation coefficient between the values of parameters obtained in subsequent measurements and independent variables (engine load) according to the formula:

$$
k=\frac{\sum_{i=1}^{n}\left(x_{i}-\bar{x}\right)\left(y_{i}-\bar{y}\right)}{\sqrt{\sum_{i=1}^{n}\left(x_{i}-\bar{x}\right)^{2} \sum_{i=1}^{n}\left(y_{i}-\bar{y}\right)^{2}}}
$$

where:

$i \quad-\quad$ the sequence number of the input or output quantities,

$x_{i} \quad-\quad$ another value of the input size,

$\bar{x} \quad-\quad$ average value of the input volume in the set of observations,

$y_{i} \quad-\quad$ successive value of a given diagnostic parameter,

$\bar{y} \quad-\quad$ average value of the given diagnostic parameter.

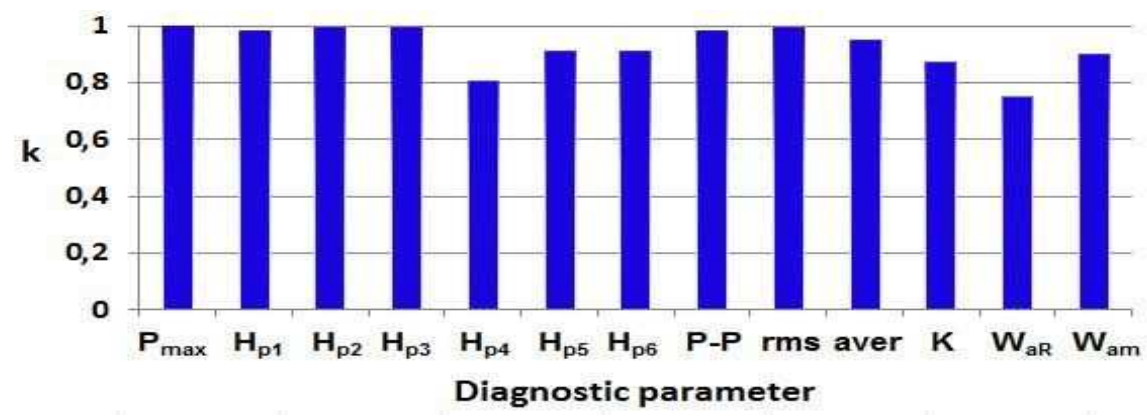

Fig. 4. Values of the correlation factor between exemplary diagnostic parameters and relative engine load: Pmax -the maximum value of the pressure course in the injection subsystem, Hp $1 \div$ Hp6 - amplitude components of the pressure spectrum in the injection subsystem, WaR - wavelet range, Wam - wavelet max 
Values of the correlation coefficient for assessment of the usefulness of exemplary diagnostic parameters in time, amplitude, frequency and wavelet domain indicated the Fig. 4. The values of the correlation coefficient in the scope of very strict compounds (over 0.9) were considered as useful. Most parameters meet this criterion.

\section{Conclusion}

The article presents the criteria for selecting the test object on the example of the marine vessels. The analysis of adverse events in sea-going vessels should take into account both the number of damages, the economic technical aspects and the risk. The selected objects of seagoing ships are combustion engines and their elements are injectors.

Methods for selection of measurement points using the criterion of reliability and preliminary test results are presented. The input quantities in the preliminary diagnostic tests of the marine combustion engine are: relative load of the engine (measured setpoint, of fuel dose, etc.), in the basic research the technical condition of the engine. In the conducted research, a static, determined plan was used.

The possible solutions for the reduction of measurement sizes and methods of data analysis have been pointed out.

In order to obtain the reasonable amount of information about the state of the tested combustion engine, it was selected by means of experimental design methods: experiment type, relevant elements, location of measurement sensors, measured quantities, test conditions, measurement frequencies, measurement data analysis and inference methods, etc.

This research outcome has been achieved under the research project "Ecological and economic aspects of the operation of selected elements of marine power systems" No. 1/S/IESO/2014 financed from a subsidy of the Ministry of Science and Higher Education for statutory activities.

\section{References}

1. Blasco J., Duran-Grados V., Hampel M., Moreno-Gutierrez J. Towards an integrated environmental risk assessment of emissions from ships' propulsion systems. Environ International, USA, 66. Pp. 44-47, (2014)

2. Chłopek Z. Some remarks on engines testing in dynamic states. Combustion Engines, Poland, pp. 60-71, (2010)

3. Girtler, J., Kuszmider, S. \& Plewiński, L.: Selected issues of the operation of ships in the safety aspect of the navigation, Maritime University of Szczecin, Szczecin (in Polish), (2003)

4. Grzywaczewski Z.: Reliability of ships, WEMA Machine Industry Publishers, Warsaw (in Polish), (1988)

5. Guan C., Theotokatos G., Chen H. Analysis of two stroke marine diesel engine operation including turbocharger cut-out by using a zero-dimensional model, Energies, Switzerland, 8, pp. 5738-5764, (2015)

6. Kontovas, C.A., Psaraftis, H.N. Formal safety assessment: a critical review, Marine Technology, USA, 46, 1, pp. 45-59, (2009)

7. Korzyński M.: Experiment methodology, WNT, Warsaw (in Polish), (2013)

8. Leszek W.: Selected methodical issues of empirical research. Library of Exploitation Problems, Radom (in Polish), (2006).

9. Monieta J.: Choice of most deceptive functional system and sub-assembly of marine diesel engines. Increasing the Work Efficiency of Energy Systems. International Collection of Scientific Works. Kaliningrad, Russia, pp. 141-146, (2002) 
10. Monieta J. Estimation of undesirable events in operation of bulk carriers. Journal of KONES Powertrain and Transport, Poland, 20, 2, pp. 291-297, (2013)

11. Monieta J. The application in-cylinder pressure course in different domains for diagnostics of medium speed marine diesel engines in operation conditions. Combustion Engines, Poland, 3, 154, pp. 104, cd. pp. 153-160, (2013)

12. Tarełko W.: Methodology of designing exploitation properties of complex technical objects, Library of Problems of Exploitation, Gdynia - Radom (2011)

13. Tomaszewski F., Szymanski G.M. Frequency Analysis of vibrations of the internal combustion engine components in the diagnosis of engine processes. The Archives of Transport, Poland, 24, pp. $117-125$, (2012)

14. Zadrąg R. Kniaziewicz T. Utilization of the zero notarizations method for the building of a ranking for diagnostic marine engine parameters. Combustion Engines, Poland, 171, 4, pp. 44-50, (2017)

15. Żółtowski B., Cempel C.: Engineering of diagnostics machines. Polish Society of Technical Diagnostics, Warsaw, Bydgoszcz, Radom (in Polish), (2004) 